\title{
Enhancing dental electives through participatory research
}

Niall Rogerson, Kate McKenna, Louise Robinson, Callum Wemyss, Jeremy Bagg, Catherine Bovill*

University of Glasgow, University of Edinburgh*

\section{Introduction}

The elective study programme is a core element of the undergraduate curriculum at the University of Glasgow Dental School, with satisfactory completion a requirement for graduation. The four-week elective study period at the end of fourth year enables students to choose either to remain in Glasgow or travel elsewhere in order to experience enquiry-led learning for personal and professional development and encourages the seeking of intellectual rigour, the desire for feedback and an awareness of the value of self-reflection. Each elective project is assessed through verbal presentation to staff members of a poster, a process that aims to develop and assess students' communication skills.

The present study was triggered by concerns expressed by some returning students who had undertaken projects abroad in low- and middle-income countries (LMICs). These concerns were expressed at a time when medical and dental international health electives (IHEs) were coming under increasing scrutiny in professional networks, owing to a growing awareness of, and sensitivity to, the challenges within the context of global health and social justice, including massive health inequities, poverty and cultural differences (Dowell and Merrylees, 2009; Han and Quiñonez, 2013; Hanson et al, 2011).

Discussions with students returning from electives in LMICs identified three core issues of concern: first, there was a range of ethical issues, particularly in relation to the quality of clinical supervision, which was often deemed inadequate for unqualified dentists, therefore perhaps compromising the quality of patient care; second, the shortcomings in supervision resulted in concerns about the educational value of the experience; third, the issue of student safety was a major concern, particularly for those undertaking clinical activities which could result in a sharps injury when access to occupational health services might be uncertain.

These concerns were taken seriously, particularly since this type of elective experience had become increasingly popular at the School, with $62 \%$ of fourth-year students in 2012 undertaking elective projects involving clinical interventions in low-resource overseas locations. It was clear that the School could not quality assure such activities, making it impossible to assess the value that might be added to local health care provision or to the personal and professional development of the students. Consequently, in 2014, the School decided no longer to permit undergraduates to undertake elective overseas projects that involved exposure-prone procedures (EPPs), unless within a clinical environment that had been appropriately risk-assessed through a formal University partnership.

Cessation of this type of elective in LMICs was initially not well received by some students. It was against this backdrop that the present study was established, to explore students' elective expectations and what they would like to gain from their elective activities. A participatory methodology was chosen, that: enabled students' views to be embedded in every aspect of the research; strengthened validity; offered the potential for delivering highly- 
relevant outcomes; provided the additional benefit for co-researchers of developing research skills and graduate attributes consistent with the developmental ethos of elective study (Olitsky and Weathers, 2005; Seale, 2010; Smit, 2013).

The aim of this qualitative study was to establish what dental students perceive to be the potential benefits of undertaking an elective project. The outputs would inform quality enhancement of the existing dental elective programme. Indeed, Becket and Brookes (2006) favour qualitative data over quantitative data to provide a 'clear explanation' which 'can more readily inform decision making for quality enhancement purposes' (p. 128).

\section{Methods}

The principal objective of the study was to generate new knowledge to inform change across the dental elective programme in a manner consistent with the principles of meaningful participation and social justice. Furthermore, as there is a paucity of published literature related to dental electives, the study sought to gather evidence at a local level. The authors recognised that any study which aims to investigate and enhance an elective programme must have the students at the centre of the enquiry process and hence the choice of a participatory methodology (Cornwall and Jewkes, 1995; Hall, 1981; Hall, 1992; Moore, 2004; Stoecker and Bonacich, 1992), ensuring that, as Moore (2004) advises, the research is 'grounded in the community that the research involves' (p. 147). Students are increasingly regarded as partners, co-creators and even experts in higher-education learning experiences (Cook-Sather et al, 2014) and can be recruited as co-evaluators providing feedback on areas of curricula (Bovill et al, 2010; Kay et al, 2010), as described in the present study. Furthermore, the intention was to engage the student co-researchers in an authentic research experience and for them to feel part of the research culture of the University (Taylor and Wilding, 2009). There was an established and trusting relationship between the student co-researchers and focus-group student participants. The issue of maintaining confidentiality of responses and views was stressed within the co-research team, as emphasised within literature on insider research (Gibbs, 1997; Mercer, 2007).

\section{Ethical approval}

Ethical approval was obtained from the University of Glasgow College of Social Sciences Ethics Committee. The Committee was satisfied that the potential benefits justified the project, and that the design of the study, including voluntary recruitment of student participants, was not unduly influenced by the dependent student-staff relationship (Olitsky and Weathers, 2015; Gibbs, 1997; Mercer, 2007; Christians, 2011).

\section{Establishment of study team}

Cornwall and Jewkes (1995) argue that the key element of participatory research lies not in methods but in the attitudes of researchers, which in turn determine how, by and for whom research is conceptualized and conducted' (p. 1667). They also stress the importance of 'deep participation', ideally at a collegiate level, with the 'location of power' tipping towards the participants (pp. 1667-1669). Mindful of these precepts, on the basis that they had previously been elected by their peers as class representatives, three Bachelor of Dental Surgery (BDS) fourth-year undergraduate students (two female, one male), were invited to work as co-researchers with the staff researcher (male). The incentive was that they would contribute very significantly to the development and enhancement of an important element of 
the curriculum and would have the opportunity to co-author a paper. This established a study team of four, which met regularly to plan and undertake data collection, share data analysis tasks and progress the study. The students learned about the key principles of participatory research and focus-group data collection and the staff researcher recommended that the coresearchers read papers by Cornwall and Jewkes (1995), Moore (2004) and Gibbs (1997), as well as view examples of focus-group sessions on YouTube.

\section{Data collection}

Both a questionnaire and a focus group were used to collect data from the cohort of fourthyear students who were about to undertake their elective study. The questionnaire was administered by email as the first phase of the research and the analysis of the data it yielded informed the topic areas that were explored in depth during the focus-group meeting in the second stage of the research.

\section{Questionnaire}

As this study was exploring complex issues with many possible responses, open-ended (with one exception) questions were used that Bell (2010) and Cohen et al (2007) argue enable respondents to explain their answers and add comments. The following eight openended questions were piloted and, following some minor amendments, were subsequently used:

- What does an elective experience mean to you?

- How did you acquire your current knowledge of elective study?

- Why do you think an elective is a course requirement?

- How did you choose your elective topic?

- How will your topic benefit you academically?

- How will your topic benefit your future career?

- How will your topic benefit you personally?

- Any other comments or suggestions?

Finally, students were asked to rate, on a Likert scale, their responses to the phrase: 'the elective opportunity is a worthwhile undergraduate activity'. This provided a numerical result on an ordinal scale.

An email outlining the relevance of the questionnaire and the study was sent to all eightyseven fourth-year students' University email accounts. The students were invited to participate and provide their responses anonymously via an electronic link. As a way of encouraging participation, the co-researchers both utilised social media and made announcements to their peers on several occasions after lectures. In total, thirty-four students completed the questionnaire.

The questionnaire was administered through the Dental Elective domain in the School's Virtual Learning Environment (Moodle), a system with which the students were familiar and which has the capability to manage questionnaire responses electronically and anonymously. The questionnaire was short, contained questions considered by the coresearchers to be relevant and stipulated a deadline, all characteristics which have been shown to result in improved response rates (Edwards et al, 2010). Electronic data on Moodle 
were imported to a Microsoft Excel spreadsheet, then converted to a Word document and printed for coding and analysis by the research team. The analysis was influenced by the six-step process recommended by Lichtman (2013) to move from coding through categorising to concepts. Key and recurring themes were identified as worthy of further exploration and teased out to inform questions for the focus group. To enhance reliability within the data analysis, all members of the team analysed several data extracts to check for consistency, following guidance from author six, based outside the Dental School.

\section{Focus group}

The purpose of the focus group was to get close to the experiences of the participants and develop an understanding of 'what the students thought' as they prepared for their elective. The student co-researchers sent an email to the entire year four class, thanking those who had responded to the questionnaire and inviting volunteers to participate in a focus-group meeting. Seven students responded positively and subsequently participated in the focusgroup discussion, which was facilitated by the three fourth-year co-researchers, so ensuring the principle of high-level participation and avoiding the perception of a staff-led forum. Focus-group participants were assured that all data would be treated confidentially and that they would not be recognisable in any report, presentation or publication arising from this work. Each of the participants provided her/his consent to be involved.

Questionnaire analysis identified the following aspects as appropriate themes for discussion:

- influence of elective geographic location or topic of interest;

- career-enhancing graduate attributes: research or work experience;

- contribution to social justice / citizenship / global health;

- student-organised / student-led or University-arranged / institutional links;

- elective at end of BDS three rather than BDS four;

- option of two-year elective leading to BDS honours / masters;

- downsides / negative aspects / burden;

- if not compulsory, how would you use the time?

- method of assessment.

The focus-group discussion lasted one hour, with the staff researcher observing and making notes. The discussion was also audio-recorded and transcribed by the staff researcher; the completed transcript was sent by email to the co-researchers and focus-group participants for verification. 


\section{Results}

\section{Questionnaire findings}

Of the eighty-seven fourth-year students who were sent the anonymous link to the questionnaire, thirty-four (39\%) responded.

When analysing questionnaire data (and the focus-group data below), the researchers noticed that certain themes were regarded as important and mentioned often, such as 'motivators' for choosing a particular elective (for example, gaining clinical experience, visiting a particular country or learning about a particular topic); this enabled the researchers to describe quantitatively some commonly-stated views.

The most common responses are summarised in Table 1. There was a general belief that completion of an elective would evidence personal, social and professional development and demonstrate organisational, analytical, interpersonal and communication skills, supporting its inclusion as a course requirement.

The choice of elective topic arose, for the most part, from particular interests and elements of dentistry which individual students found especially enjoyable. The cessation of projects involving EPPs was regretted by some; however, this had motivated students to think in more depth about their potential elective topic.

A strong theme that emerged was the enthusiasm for learning how to conduct research, including aspects such as applications for ethical approval and report writing. The potential value of high-quality elective projects to enhance curricula vitae (CV), particularly in relation to specialty training later in students' careers, was also cited frequently.

Many positive personal benefits were reported, including meaningful reflection, an enthusiasm for grasping learning opportunities and a keen awareness of responsibilities as health professionals at the beginning of careers. Whilst there was disappointment among a minority at the cessation of clinical electives abroad that involved EPPs, there were both acceptance of the rationale for this decision and an understanding that many other elective choices were still available. Overall, $85 \%$ either agreed or strongly agreed that the elective opportunity is a worthwhile undergraduate activity. Inductive analysis of the responses to these nine questions identified emerging common themes that were explored in depth during the focus-group discussion. 
Table 1. Summary of responses to open questions in the questionnaire

\begin{tabular}{|c|c|}
\hline Question & Commonly-stated views (number of responses) \\
\hline $\begin{array}{l}\text { What does an elective experience mean } \\
\text { to you? }\end{array}$ & $\begin{array}{l}\text { Opportunity to select a topic of special interest to study in depth 'to push the } \\
\text { boundaries of our studies' (25) } \\
\text { To travel and learn in a location, institution and culture outside Glasgow, 'to } \\
\text { experience a different culture of dentistry' and 'go abroad and have some great } \\
\text { experiences' (13) }\end{array}$ \\
\hline $\begin{array}{l}\text { How did you acquire your current } \\
\text { knowledge of elective study? }\end{array}$ & $\begin{array}{l}\text { 'Word of mouth' from senior students, staff and other dental colleagues; 'starting } \\
\text { dental school in BDS1, electives are a commonly discussed subject' (32) } \\
\text { Lectures and teaching events ( } 21 \text { ) } \\
\text { Virtual Learning Environment (Moodle) resources (12) }\end{array}$ \\
\hline $\begin{array}{l}\text { Why do you think an elective is a course } \\
\text { requirement? }\end{array}$ & $\begin{array}{l}\text { An opportunity for student-led and self-directed independent learning (21) } \\
\text { A means to 'allow', 'encourage' or 'force' students to identify and pursue their own } \\
\text { topics of interest (14) }\end{array}$ \\
\hline How did you choose your elective topic? & $\begin{array}{l}\text { Two main overlapping categories: 'existing interest' and 'enjoyment / appeal of a } \\
\text { topic' (27) } \\
\text { Discussions with influential dental school staff (7) } \\
\text { Attraction of a particular elective location (6) } \\
\text { 'Helping others' and 'contribution to the community' (5) }\end{array}$ \\
\hline $\begin{array}{l}\text { How will your topic benefit you } \\
\text { academically? }\end{array}$ & $\begin{array}{l}\text { Expectation of gaining new 'knowledge' or greater 'understanding' of various dental } \\
\text { specialties (13) } \\
\text { Developing specific skills e.g. presentation, communication, literature reviewing, } \\
\text { critical appraisal, peer-assisted learning, self-directed learning and team working } \\
\text { (11) } \\
\text { Emphasis on learning research skills (10) }\end{array}$ \\
\hline $\begin{array}{l}\text { How will your topic benefit your future } \\
\text { career? }\end{array}$ & $\begin{array}{l}\text { Many respondents (16) were looking ahead to postgraduate specialist training or an } \\
\text { academic post and hoped an elective placement might help them decide if they were } \\
\text { suited (8) } \\
\text { Enhancement of CV (16) }\end{array}$ \\
\hline $\begin{array}{l}\text { How will your topic benefit you } \\
\text { personally? }\end{array}$ & $\begin{array}{l}\text { Extremely positive responses, citing benefits from personal reflections (17), } \\
\text { enhanced interpersonal skills (11), experience of other cultures (11), learning in a } \\
\text { specific area of interest (10) }\end{array}$ \\
\hline Any other comments or suggestions? & $\begin{array}{l}\text { Disappointment at the cessation of overseas electives in LMICs involving EPPs (4) } \\
\text { Varied views on the potential for the elective period to be earlier in the course at the } \\
\text { end of BDS3 } \\
\text { Consideration of two elective periods, or the opportunity to undertake more } \\
\text { substantial research-based electives (2) }\end{array}$ \\
\hline
\end{tabular}


Table 2. Likert scale responses to the question: To what extent do you agree with the statement 'Overall, the elective opportunity is a worthwhile undergraduate activity?

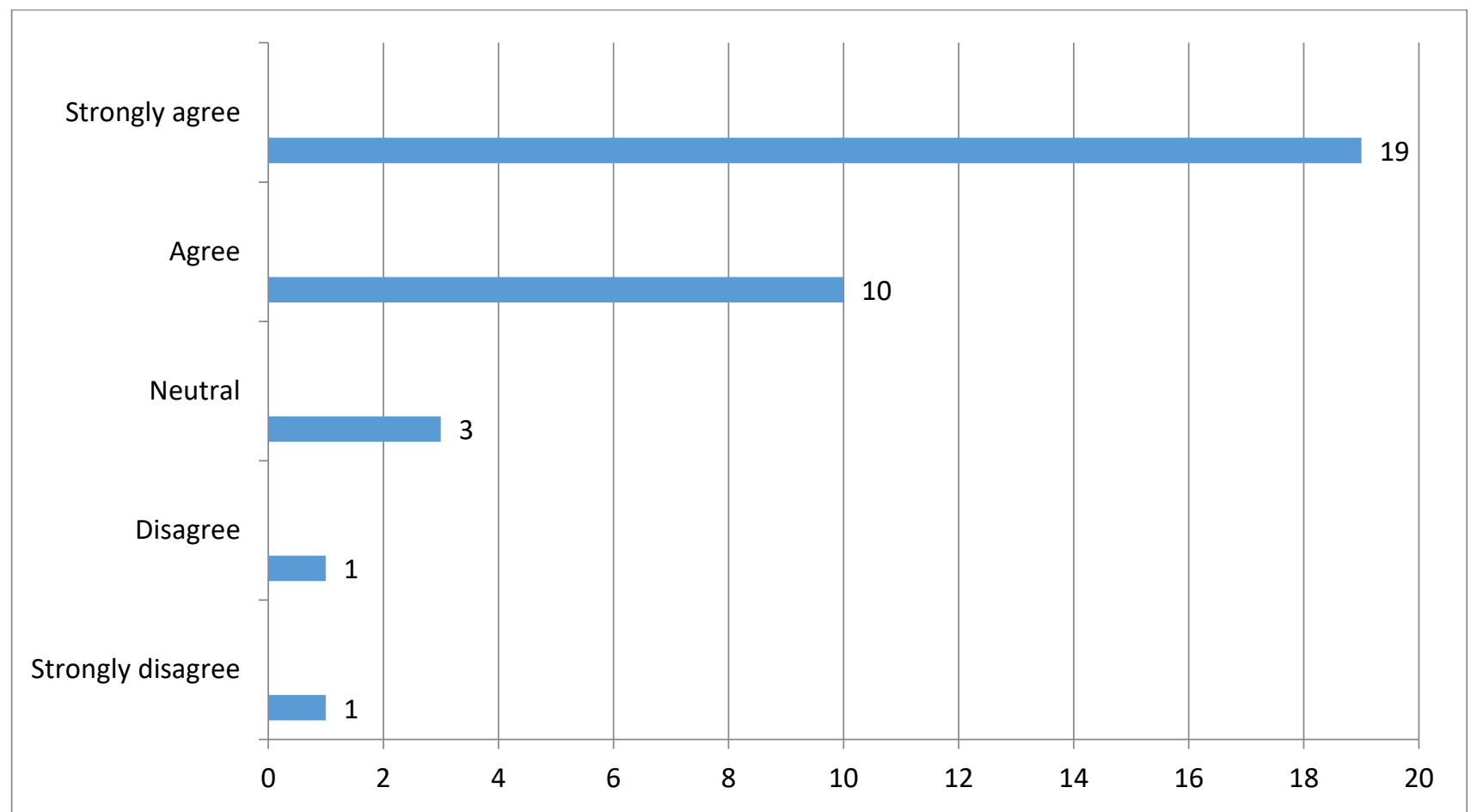

Note: The respondent who selected 'strongly disagree' had commented favourably in free text responses; it is possible that the respondent made a data entry error.

\section{Focus-group findings}

The focus-group findings served to provide a deeper understanding of the questionnaire findings and also contributed new knowledge. The seven focus-group participants were planning a diverse range of electives both in the UK and abroad, which was representative of commonly-selected topics, including public health, overseas observational health elective, dental research and university student exchange. The findings are presented in relation to the areas of questioning that were used to provide a loose structure for the focus-group discussions.

\section{Influence of elective geographic location or topic of interest}

Geographic location and topic of interest were viewed as equally important. In agreement with the questionnaire responses, the focus-group participants perceived the restrictions on EPPs abroad as having the effect of requiring students to be more imaginative in their choice of elective.

\section{Career-enhancing graduate attributes: research or work experience}

The majority of participants viewed the elective as an activity that could be linked with graduate attribute development. It was also an opportunity to test out future career options. Adding a distinctive section to individual students' CVs was viewed as important. The prescriptive nature of the BDS programme dictates that the academic and clinical 
experiences of most students are similar, but the elective provides an opportunity to demonstrate more personal achievement to future employers.

\section{Contribution to social justice/citizenship/global health}

The Dental School's decision to restrict overseas clinical electives in LMICs to those that did not involve EPPs had been explained and justified to this cohort of students during elective presentations and discussions. Most participants recognised that health improvement projects and those examining oral health interventions had the potential to be more beneficial to global health improvement than previous projects where students were undertaking multiple dental extractions. The participants also recognised that some of the commercial elective placement organisations were potentially more interested in profitability than the quality of the elective experience or healthcare being delivered.

The discussion highlighted varied awareness of whether there was an equitable and reciprocal transfer of benefits - a variable degree of recognition that the greater benefit may flow from an LMIC to the UK, rather than from the UK to LMIC populations. Some participants did recognise this and suggested that global health education should be included in the BDS curriculum.

\section{Student-organised/student-led or University-arranged institutional partnerships}

There was a general consensus that, although it was very important for students to be able to select their own topic, an elective could also be facilitated by the University's establishing institutional links. A University-organised placement, coupled with a student-selected topic, was described very positively. This model was already available through a formal exchange programme with Sun Yat Sen University in Guangzhou, China. This international institutional partnership was particularly valued, with the host student group from each Dental School providing peer support for the other on reciprocal visits to their institutions. Participants argued that establishment of additional formal institutional links and student exchange opportunities would be highly valued, with students retaining their independence to choose their own topics.

\section{Timing of elective project}

The focus group rapidly agreed that the timing of the elective at the end of year four was appropriate and convenient. The overall opinion was that insufficient clinical experience and a lower level of professional maturity would mean that an elective earlier in the course would be of less value.

\section{Option of two-year elective leading to BDS honours/masters}

When preparing for the focus-group discussion, the co-researchers had considered the possibility that an elective study could contribute to gaining an honours or Masters degree. However, the focus-group participants argued that the current provision of intercalated degrees, BDS with honours based on academic and clinical performance, and the existing arrangements for a Masters degree provided sufficient opportunities. 


\section{Downsides, negative aspects, burden}

Whilst the participants were enthusiastic about the elective programme and the wide choice of topic areas available, a common view was that it would be helpful to have examples of pathways to aid navigation through the planning process for projects of each particular type, ensuring avoidance of unnecessary complications.

\section{If not compulsory, how would you use the time?}

Despite the awareness that the elective addressed essential intended learning outcomes for the BDS programme, there was discussion about whether completion of an elective project should be optional. The conclusion was that, even if it were optional, most students would still choose to undertake a project and that it would be hard to justify non-participation at a subsequent job interview. However, as an alternative to an elective, additional clinical time in the Dental School, gaining further operative experience within its quality-controlled teaching environment, was felt worthy of consideration.

\section{Method of assessment}

The assessment process via a poster presentation was almost unanimously commended. With one exception, the participants were comfortable with giving a verbal presentation and were very positive, regarding this as an opportunity to develop new skills such as poster writing, with plenty of scope to showcase their elective experiences.

\section{Discussion and conclusions}

There is a relative paucity of published literature related to dental electives and very few studies directly relevant to student perceptions of their value. An article by Walmsley et al (2007) in the British Dental Journal about a staff/student elective workshop stated: 'for an elective to be successful, aims should be set and the elective should be assessed formally'. The students were clear that 'electives should retain freedom and openness and belong to the student, not to the staff' (p. 221); they strongly supported their continuation.

Health and safety of students during elective placements was a tangible concern shared by staff and some of the students in this study. In addition to the risk of sharps injuries and other clinical incidents, the behaviours of students might place them at increased risk of accident, with potentially more serious consequences when abroad. Tyagi et al (2006, p. 155), in a 2003 survey of United Kingdom medical schools, recorded the following, occurring during, or shortly after, elective placement: seven traumatic deaths, five serious non-fatal road traffic accidents, seven students injured as a consequence of crime and numerous reports of non-fatal infectious disease unlikely to be related to clinical activity.

One particular issue which was vigorously debated during the focus-group discussion was the cessation of electives that involved clinical procedures abroad and this highlighted lacunae related to how sending institutions can best engage internationally. How can dental schools ensure an equitable elective process that will benefit the host community? Currently, most of the published literature pertains to medical electives. Elit et al (2011) identify 'a range of ethical challenges', including 'uncertainty about how best to help', 'questions around scope of practice' and 'difficulties in navigating different cultures of medicine' ( $p p$. 709-710). 


\section{Research articles}

Banerjee (2010) and Edwards et al (2004) recognise that western medical schools and students have traditionally viewed this type of elective as an opportunity to engage with world health issues during the undergraduate medical course. However, these authors stress that electives should be viewed as part of a comprehensive global health educational programme embedded in the curriculum.

The educational value of an IHE is questioned by Dowell and Merrylees (2009) who state: 'the academic literature on the educational effect of electives is surprisingly sparse' (p. 122); they recommend 'that the benefits for students could be substantially increased and negative effects minimised with suitable planning and preparation' (p. 123). On a more positive note, Thompson et al (2003) suggest an association between IHEs and medical students' future career choices in under-served communities and primary care specialties. Dickson and Dickson (2005, p. 868) raise an important point for elective students contemplating an IHE. Do you have to travel to an overseas location, or can you usefully volunteer at home? It is possible to 'think globally, act locally'. In summary, both the literature and this study's findings strongly indicate that further research is required before clinical IHEs can be unquestioningly endorsed.

The overarching impression from the findings is of marked positivity towards the elective programme; this is demonstrated by the enthusiastic participation of the student coresearchers and also supported by questionnaire and focus-group data. The authors' view is that the richness of the data was enhanced by the students' speaking more openly with the co-researchers. Their idea and ability to advertise the questionnaire and focus group, using social media and announcements after lectures, and their genuine interest in hearing the views of students in their year to inform decisions affecting future electives, improved participation. This commitment to develop the elective programme was also demonstrated by the insightful conversations of the focus-group participants.

The study has provided evidence of current good practice but also identified areas that would benefit from change. Aspects of the electives which are particularly valued can be maintained: for example, the scope of opportunities, timing of the elective and the method of assessment have been generally commended. Enhancement can be achieved by developing autonomy, with students encouraged to select topics which are especially meaningful to them as individuals. The School can facilitate these projects with suitable levels of guidance, including, where possible, institutional links tailored to students' specific elective requirements.

The findings demonstrate clearly that students require sufficient time to understand the concept and purpose of elective study, to develop ideas through an iterative process and to have conversations with a wide variety of individuals and plenty of time for reflection. The intention is that many of the recommendations noted below will underpin the elective preparation process and further embed the elective programme within the University of Glasgow BDS curriculum; for example, by introducing global health education during year two, to help to promote awareness of international issues in relation to elective studies.

The intended outcomes of the study are enhanced educational benefits, to inform a quality assurance and enhancement process and to add value when students engage with the wider community. Key to addressing these outcomes is for students to engage effectively with the range of technical and human resources available within the University and in other 


\section{Research articles}

institutions. Effective quality assurance and enhancement may be further developed by introducing semi-structured debriefing sessions for returning elective students and applying student feedback to benefit the next cohort and inform future policy. Watson (2003) stresses student feedback as an important element for quality assurance.

The student co-researchers wrote highly-positive research-experience reflections, related to the opportunities provided by being co-researchers and authors of this study, and outlined a range of skills they have developed as a result. Notable outcomes include co-authoring a poster for an international medical education conference, co-presenting the work at an invited learning-and-teaching seminar and experience of co-authoring this paper.

It is acknowledged that the study had limitations. Ideally, the student co-researchers would have been recruited before decisions about the research questions and research methods were made, allowing a deeper level of participation, as advocated by Cornwall and Jewkes (1995). To enhance the rigour of the study, validation of focus-group transcripts and analyses by the focus-group participants and other qualitative researchers could have been undertaken had more time been available (Burnard et al, 2008; Ritchie et al, 2005).

In summary, the research has resulted in the following recommendations. The Dental School acknowledges the unique and valuable perspectives of all the students who participated in this research, on which these recommendations are based. In discussion with staff and within the context of the Dental School's strategic plan, these recommendations will be enacted in order to enhance the benefits of the Dental Elective Programme:

1. Debriefing and feedback sessions should be formalised for returning elective students.

2. There should be active student participation in the Dental Elective Committee.

3. Various methods should be used to raise awareness of the Dental Elective programme for junior students, enabling very early preparation.

4. Wider dissemination of completed elective projects should be encouraged; e.g. student-led elective presentation events.

5. The School should continue to support the widest possible range of elective projects.

6. The independence and autonomy of the elective student should be protected.

7. The School should progress the establishment of institutional links with organisations both within and outside the UK to support dental elective opportunities.

8. The School should continue to develop elective exchange programmes as an important aspect of internationalisation.

9. Electives in LMICs should be supported by global health education early in the curriculum, especially highlighting the ethical perspective.

10. Further research is required before IHEs involving clinical procedures can be supported.

11. Sufficient time and resources should be identified to enable the Dental Elective Committee to implement these recommendations. 
Research articles

\section{Reference list}

Banerjee, A. (2010) 'Medical electives: a chance for international health.' Journal of the Royal Society of Medicine, 103, 6-8.

Becket, N. and Brookes, M. (2006) 'Evaluating quality management in university departments.' Quality Assurance in Education, 14(2), 123-142.

Bell, J. (2010) Doing your research project. Maidenhead: Open University Press, 140-157.

Bovill, C., Aitken, G., Hutchison, J., Morrison, F., Roseweir, K., Scott, A. and Sotannde, S. (2010) 'Experiences of learning through collaborative evaluation from a postgraduate certificate in professional education.' International Journal for Academic Development, 15(2), 143-154.

Burnard, P., Gill, P., Stewart, K., Treasure, E. and Chadwick, B. (2008) 'Analysing and presenting qualitative data.' British Dental Journal, 204, 429-432.

Christians, C.G. (2011) 'Ethics and politics in qualitative research.' In: Denzin, N.K. (ed.), Lincoln, Y.S. ( $4^{\text {th }}$ ed.). The SAGE Handbook of qualitative research. London: SAGE, 61-80.

Cohen, L., Manion, L. and Morrison, K. (2007) Research Methods in Education (6 $6^{\text {th }}$ ed.). London: Routledge.

Cook-Sather, A., Bovill, C. and Felten, P. (2014) Engaging students as partners in learning and teaching: a guide for faculty. San Francisco: Jossey Bass.

Cornwall, A. and Jewkes, R. (1995) 'What is Participatory Research?' Social Science and Medicine, 41(12), 1667-1676.

Dickson, M. and Dickson, G. (2005) 'Volunteering: Beyond an act of charity.' Journal of the Canadian Dental Association, 71, 865-869.

Dowell, J. and Merrylees, N. (2009) 'Electives: isn't it time for a change?' Medical Education, 43, 121-126.

Edwards, P.J., Roberts, I., Clarke M.J., DiGuiseppi, C., Wentz, R., Kwan, I., Cooper, R., Felix, L.M. and Pratap, S. (2010) 'Methods to increase response to postal and electronic questionnaires (Review).' The Cochrane Collaboration and published in The Cochrane Library: 2010, 1, 1-12.

Edwards, R., Piachaud, J., Rowson, M. and Miranda, J. (2004) Understanding global health issues: are international medical electives the answer?' Medical Education, 38, 688-690.

Elit, L., Hunt, M., Redwood-Campbell, L., Ranford, J., Adelson, N. and Schwartz, L. (2011) 'Ethical issues encountered by medical students during international health electives.' Medical Education, 45, 704-711.

Gibbs, A. (1997) 'Focus Groups.' In: Social Research Update: Department of Sociology: University of Surrey, 19, 1-7. Guildford: University of Surrey. 
Hall, B.L. (1981) 'Participatory research, popular knowledge and power: a personal reflection.' Convergence, 14 (3), 6-19.

Hall, B.L. (1992) 'From Margins to Centre? The Development and Purpose of Participatory Research.' American Sociologist, 15-28.

Han, S.J. and Quiñonez, C.R. (2013) 'Dental Volunteerism: Is the Current Model Working?' Journal of the Canadian Dental Association, 79(4), 205-207.

Hanson, L., Harms, S. and Plamondon, K. (2011) 'Undergraduate International Medical Electives: Some Ethical and Pedagogical Considerations.' Journal of Studies in International Education, 15(2), 171-185.

Kay, J., Dunne, E. and Hutchinson, J. (2010) Rethinking the values of higher education students as change agents? The Quality Assurance Agency for Higher Education. Available at: http://www.qaa.ac.uk/en/Publications/Documents/Rethinking-the-values-of-highereducation---students-as-change-agents.pdf. (Accessed: 01 June 2014).

Lichtman, M. (2013) Making Meaning from Your Data: Chapter 12. Qualitative Research in Education: A User's Guide. London: SAGE.

Mercer, J. (2007) 'The challenges of insider research in educational institutions: wielding a double-edged sword and resolving delicate dilemmas.' Oxford Review of Education, 33(1), $1-17$.

Moore, J. (2004) 'Living in the Basement of the Ivory Tower: a graduate student's perspective of participatory action research within academic institutions.' Educational Action Research, 12(1), 145-162.

Olitsky, S. and Weathers, J. (2005) 'Working with Students as Researchers: Ethical Issues of a Participatory Process.' Forum: Qualitative Social Research, 6(1), 1-17.

Ritchie, J., Spencer, L. and O'Connor, W. (2005) 'Carrying out Qualitative analysis.' In: Ritchie, J. and Lewis, J. (eds.) Qualitative Research Practice: A Guide for Social Science Students and Researchers. London: SAGE.

Seale, J. (2010) 'Doing student voice work in higher education: an exploration of the value of participatory methods.' British Educational Research Journal, 36(6), 995-1015.

Smit, B.H.J. (2013) Young people as co-researchers: enabling student participation in educational practice.' Professional Development in Education, 39(4), 550-573.

Stoecker, R. and Bonacich, E. (1992) 'Why Participatory Research?' American Sociologist, 23(4), 5-10.

Taylor, P. and Wilding, D. (2009) Rethinking the values of higher education - the student as collaborator and producer? Undergraduate research as a case study. The Quality Assurance Agency for Higher Education. Available at: http://dera.ioe.ac.uk/433/2/Undergraduate.pdf. (Accessed: 01 June 2014). 


\section{Research articles}

Thompson, M.J., Huntington, M.K., Hunt, D.D., Pinsky, L.E. and Brodie, J.J. (2003) 'Educational Effects of International Health Electives on U.S. and Canadian Medical Students and Residents: A Literature Review.' Academic Medicine, 78, 342-347.

Tyagi, S., Corbett, S. and Welfare, M. (2006) 'Safety on elective: a survey on safety advice and adverse events during electives.' Clinical Medicine, 6(2), 154-156.

Walmsley, A.D., White, D.A., Hobson, R. and Ensor, S. (2007) 'The BDA Dental Academic Staff Group Student Elective Workshop.' British Dental Journal, 203(4), 220-221.

Watson, S. (2003) 'Closing the feedback loop: Ensuring effective action from student feedback.' Tertiary Education and Management, 9(2), 145-157. 